\title{
OPTIMAL GAIN OF PI SPEED CONTROLLER IN RELUCTANCE SYNCHRONOUS MOTOR USING PARTICLE SWARM OPTIMIZATION
}

\author{
M'hamed BIRAME*, Sid Ahmed BESSEDIK ${ }^{* *}$, Lakhdar MOKRANI ${ }^{* *}$, Mohamed Fouad BENKHORIS ${ }^{* * *}$ \\ ${ }^{*}$ LEDMASED Laboratory, University of Laghouat, 03000, Algeria \\ ${ }^{* *}$ LACOSERE Laboratory, University of Laghouat, 03000, Algeria \\ ${ }^{* * *}$ CRTT, IREENA, Saint Nazaire, Polytech'Nantes, France
}

\begin{abstract}
This paper presents a new direct torque control (DTC) strategy for Synchronous Reluctance Motor using the particle swarm optimization (PSO) algorithm. In conventional direct torque controlled (DTC) Synchronous Reluctance Motor (SRM), there is usually undesired torque and flux ripple. So Tuning parameter of the PI-Controller (Kp, Ki) are essential to DTC system to improve the performance of the system. In this work, particle swarm optimization (PSO) is proposed to adjust the parameters (Kp, Ki) of the speed controller in order to improve the performance of the system, and run the machine at reference speed.
\end{abstract}

Keywords: Synchronous Reluctance Machine (SRM), Direct Torque Control (DTC), Particle Swarm Optimization (PSO), PIcontrol, PI-PSO

\section{INTRODUCTION}

The $S R M$ has attracted significant interest of industry due to their main advantages are [1][2]:

- Simplicity and robustness

- High torque overloads capacity

- High efficiency over wide speed-range

- Low machine inertia

- Decreased maintenance requirements

The absence of windings and magnets on the rotor enables $S R M$ to run high speed and temperature. An SRM can produce large torque in a wide speed range.

All this reinforces the idea of the optimal design of a system of tracking in the aim to push system solar efficiency to an interval more incentive for investment.

The most modern technique is direct torque control method (DTC). The DTC offers many advantages like fast torque response, no need of coordinate transformation and less dependence on the rotor parameters [3]. The conventional PI (proportional, integral) control method is widely used in motor control system due to the simple control structure and easiness of design. However tuning the parameters of $P I$ controller is a difficult task. To enhance the capabilities of traditional $P I$ parameter tuning techniques, several intelligent approaches have been suggested such as the particle swarm optimization (PSO).

Particle Swarm Optimization (PSO) is one of the modern algorithms used to solve global optimization problems. Thus, to solve an optimization problem, PSO applies a simplified social model [4]. Compared to other methods [5], the advantages of PSO are that PSO possesses the capability to escape from local optima, it is easy to be implemented and has fewer parameters to be adjusted [6]. The PSO method is an excellent optimization methodology and a promising approach for solving the optimal PI controller parameters problem.

\section{MATHEMATICAL MODELING OF SRMOTOR}

The model adopted for the SRM suitable for DTC control is as follows [1][2].
Where

$\left\{\begin{array}{l}\frac{d I_{d}}{d t}=-\frac{R_{s}}{L_{d}}+\frac{L_{q}}{L_{d}} P \omega_{r} I_{q}+\frac{1}{L_{d}} U_{d} \\ \frac{d I_{q}}{d t}=-\frac{R_{s}}{L_{q}}-\frac{L_{d}}{L_{q}} P \omega_{r} I_{d}+\frac{1}{L_{q}} U_{q}\end{array}\right\}$

The electromagnetic torque is expressed in the same frame by:

$T_{e}=\frac{3 P}{2 J}\left(L_{d}-L_{q}\right) I_{d} I_{q}$

The motor mechanical equation is written as follows:

$J \dot{\Omega}=T_{e}-T_{r}-f_{r} \Omega$

\section{DIRECT TORQUE CONTROL OF SRM}

The DTC control is based on the direct determination of the command sequence used to switch a voltage inverter.

This choice is usually based on the use of hysteresis comparators whose function is to control the system state, namely the amplitude of stator flux and electromagnetic torque. A two levels classical voltage inverter can achieve seven separate positions in the phase corresponding to the eight sequences of the voltage inverter [1-3].

These positions are illustrated in Fig. 1. In addition Table 1 shows the sequences for each position, such as: $S_{i}=1, \ldots, 6$, are the areas of localization of stator flux vector, on the other hand, the error $\Delta \varphi$, between the reference flux and the flux estimated, is introduced into a hysteresis comparator for two levels, which delivers ' 1 ' if the error is positive and ' 0 ' if it is negative as well, the error $\Delta T_{e}$, between the reference torque and estimated torque is introduced into a hysteresis comparator for three levels that delivers ' 1 ' if positive, ' 0 ' if zero and ' -1 ' if negative.

The use of three levels to adjust the torque has been proposed to minimize the average switching frequency, because its dynamics is generally faster than the flux [1-3]. 


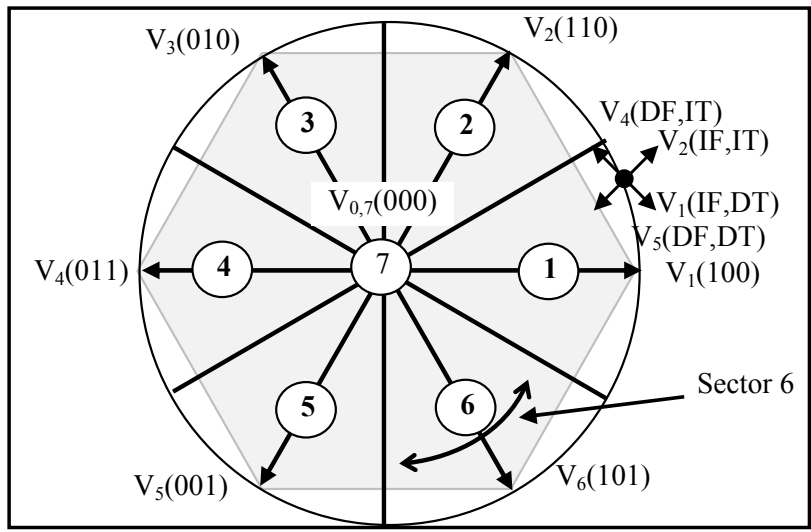

Fig. 1 Different vectors of stator voltages provided by a two levels inverter

Where:

$I(D) F$ : Increasing (Decreasing) of Flux amplitude

$I(D) T$ : Increasing (Decreasing) of Torque

The synthetic sequence can be illustrated through the following example: Assuming that the flux vector is located in sector 1 (Fig. 1), then if the error between the reference flux and the stator flux is positive, we must increase the flux this is only possible by applying a voltage vector in the same direction, according to (4) or V1(100), V2(110) or V6(101). However, applying voltages of opposite direction V3(010), V4(011) or V5(001) decreases the variation of the flux [1-3].

On the other hand, if the error between the reference torque and the electromagnetic torque is positive we must increase the electromagnetic torque by applying the voltage vectors in the half plane of positive angles, according to (5), i.e. V2(110), V3(010) or V4(011).

Trying vectors $V 1(100), V 5(001)$ or $V 6(101)$, decreases the torque.

$$
\begin{aligned}
& \bar{\varphi}_{s}(k+1) \approx \bar{\varphi}_{s}(k)+\bar{V}_{s} T_{e} \rightarrow \Delta \bar{\varphi}_{s} \approx \bar{V}_{s} T_{e} \\
& T_{e}=p\left(\bar{\varphi}_{s \alpha} i_{s \beta}-\bar{\varphi}_{s \beta} i_{s \alpha}\right)
\end{aligned}
$$

Combining these states we can decide which sequence should be applied [1-3].

Table 1 State Localization Table

$\begin{array}{cccccccc}\Delta \varphi_{\mathrm{s}} & \Delta \mathrm{T}_{\mathrm{e}} & \mathrm{S}_{1} & \mathrm{~S}_{2} & \mathrm{~S}_{3} & \mathrm{~S}_{4} & \mathrm{~S}_{5} & \mathrm{~S}_{6} \\ & 1 & 110 & 010 & 011 & 001 & 101 & 100 \\ 1 & 0 & 000 & 000 & 000 & 000 & 000 & 000 \\ & -1 & 101 & 100 & 110 & 010 & 011 & 001 \\ & 1 & 010 & 011 & 001 & 101 & 100 & 110 \\ 0 & 0 & 000 & 000 & 000 & 000 & 000 & 000 \\ & -1 & 001 & 101 & 100 & 110 & 010 & 011\end{array}$

The following diagram describes the process of DTC controlling an SRM associated with a two-level inverter supplied by controlled battery.

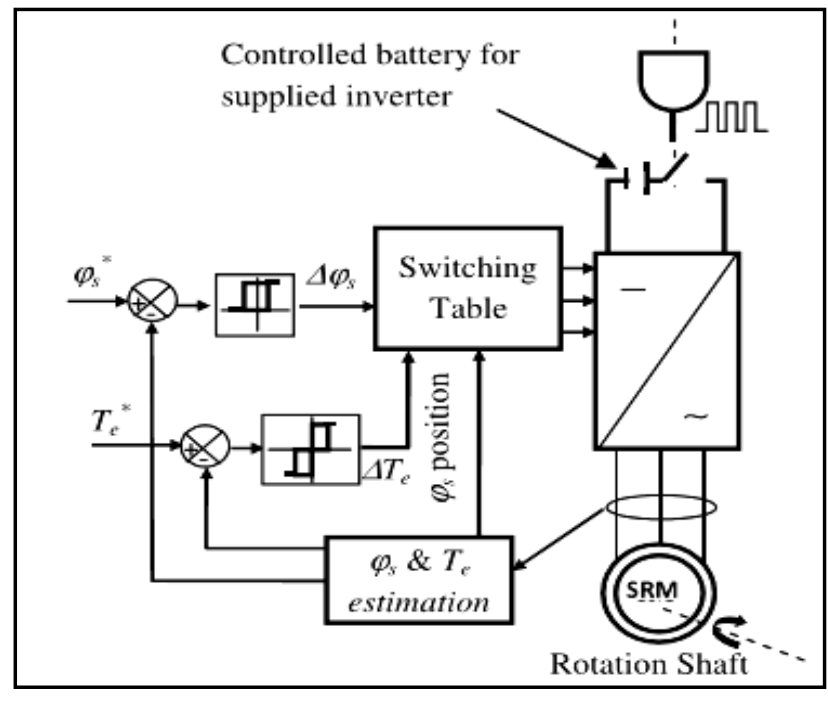

Fig. 2 Block of diagram of the DTC drive system

\section{PARTICLE SWARM OPTIMIZATION}

Particle swarm optimization is a heuristic global optimization method put forward originally by Doctor Kennedy and Eberhart in 1995. It is developed from swarm intelligence and is based on the research of bird and fish flock movement behaviour [4, 7-10].

$P S O$ has two primary operators; velocity and position update. In this paper the main objective of $P S O$ is minimization of speed error. Fig. 4 shows the block diagram for $P I$ controller and the corresponding objective function is as shown in equation (7) and (8).

\section{PSO ALGORITHM}

\subsection{Step 1: Initialization}

Each element of the swarm is initialized randomly within the effective operating limits [4][5]. $P_{\text {initial }}$ The particles are initialized as follows as given in eq. (6) and $v_{\text {initial }}$ the velocity of particles initialized as given in eq. (7)

$p_{\text {initial }}=p_{\min }+$ rand $\cdot\left(p_{\max }-p_{\max }\right)$

$v_{\text {initial }}=v_{\text {min }}+$ rand $\cdot\left(v_{\max }-v_{\max }\right)$

Where, rand is a random positive number between 0-1. [4]

$v_{\text {initial }}=\left(p_{\max }-p_{\max }\right) \cdot 0.5$

$v_{\min }=-v_{\max }$

\subsection{Step 2: Moving the particles}

The particles in the swarm are moved to new positions with the help of new velocities. The velocity and the position of the $k^{\text {th }}$ dimension of the $i^{\text {th }}$ particle are updated as follows [4][5]:

$V^{k+1}=W \cdot V^{k}+c_{1}$ rand $_{1} \cdot\left(p_{\text {best }}-S^{k}\right)+c_{2}$ rand $_{2} \cdot\left(g_{\text {best }}-S^{k}\right)$ 
$S^{k+1}=S^{k}+V^{k+1}$

$W=W_{\max }-\frac{W_{\max }-W_{\min }}{i t e r_{\max }}$. iter

Where:

$p_{\text {best }}=\left(p_{\text {best }}, p_{\text {best }}, \ldots ., p_{\text {best }}\right)$ is the best previous position yielding the best fitness value for the $i^{\text {th }}$ particle; $g_{\text {best }}=$ $\left(g_{\text {best }}, g_{\text {best }}, \ldots ., g_{\text {best }}\right)$ is the best position discovered by the whole population [4][5]. $S^{k}$ is the current position of individual. $c_{1}$ and $c_{2}$ are the acceleration constants reflecting the weighting of stochastic acceleration terms that pull each particle toward $p_{\text {best }}$ and $g_{\text {best }}$ positions,

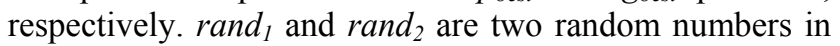
the range $[0,1] . W_{\max }$ is the initial weight, $W_{\min }$ is the final weight, iter $_{\max }$ is the maximum iteration number and iter is the current iteration position [4][5].

\subsection{Step 3: Inertia Weight Improved PSO (IWIPSO)}

In this section, for getting the better global solution, the traditional PSO algorithm is improved by adjusting the weight parameter, cognitive and social factors. Based on (8), the velocity of individual $i$ of IWIPSO algorithm is rewritten as [4]:

$$
V_{i}^{k+1}=W_{\text {new }} \cdot V_{i}^{k}+c_{1} \operatorname{rand}_{1} \cdot\left(p_{\text {best }}-S_{i}^{k}\right)+c_{2} \operatorname{rand}_{2} \cdot\left(g_{\text {best }}-S_{i}^{k}\right)
$$

$W=W_{\max }-\frac{W_{\max }-W_{\min }}{i t e r_{\max }} \cdot$ iter

$W_{\text {new }}=W_{\min }+W \cdot$ rand $_{3}$

$c_{1}=c_{1 \max }-\frac{c_{1 \max }-c_{1 \min }}{\text { iter }_{\text {max }}} \cdot$ iter

$c_{2}=c_{2 \max }-\frac{c_{2 \max }-c_{2 \min }}{\text { iter }_{\max }}$. iter

\section{Where}

$c_{1 \min }, c_{\text {lmax }}$ : initial and final cognitive factors,

$c_{2 \min }, c_{2 \max }$ : initial and final social factors.

\section{PROPOSED METHOD}

In this work we used PI controller for optimal regulation of rotor speed at the desire speed. The general block diagram of the PI speed controller is shown in Fig. 3 . The output of the speed controller (torque command) at nth instant is expressed as follows [4-5, 7-11]:

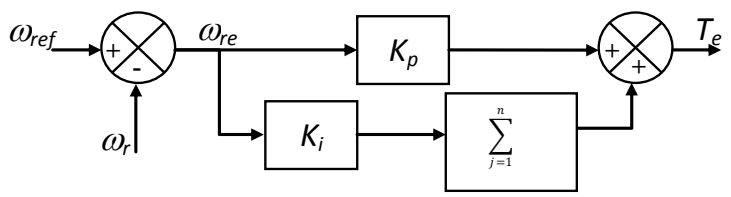

Fig. 3 PI controller

$$
T_{e}(n)=T_{e}(n-1)+K_{p} \Delta \omega_{r e}(n)+K_{i} \Delta \omega_{r e}(n)
$$

Input can be define as

$U(t)=K_{p} \cdot e(t)+K_{i} \int e(t) d t$

That $K_{i}$ and $K_{p}$ are proportional and integral coefficient in $P I$ controller.
Proportional integral $(P I)$ controller can be used to control the speed of $S R M$. The PI controller is normally avoided because differentiation can be problematic when input command is a step. Generally, the speed error, which is the difference of reference speed $\left(\omega_{\text {ref }}(n)\right)$ and actual speed $\left(\omega_{r}(n)\right)$, is given as input to the controllers. These speed controllers process the speed error and give torque value as an input. Then the torque value is fed to the limiter, which gives the final value of reference torque. The speed error and change in speed error at $n^{\text {th }}$ instant of time are given as

$\omega_{r e}(n)=\omega_{r e f}(n)-\omega_{r}(n)$

$\Delta \omega_{r e}(n)=\omega_{r e}(n)-\omega_{r e}(n-1)$

In $P I$ controller design methods, the most common performance criteria are integrated absolute error (IAE), the integrated of time weight square error (ITSE), integrated of squared error (ISE) and integrated of time weight absolute error (ITAE) that can be evaluated analytically in the frequency domain $[12,13]$. These four integral performance criteria in the frequency domain have their own advantage and disadvantages. For example, disadvantage of the $I A E$ and ISE criteria is that its minimization can result in a response with relatively small over shoot but a long settling time because the ISE performance criterion weights all errors equally independent of time. Although the ITSE performance criterion can overcome the disadvantage of the ISE criterion, the derivation processes of the analytical formula are complex and time-consuming [13]. The IAE, ISE, ITAE and ITSE performance criterion formulas are as follows [45, 7-11]:

$$
\begin{array}{ll}
I A E=\int_{0}^{T} t d t & \text { ITAE }=\int_{0}^{T} t(e) d t \\
I S E=\int_{0}^{T}\left(e^{\wedge} 2\right) d t & \text { ITSE }=\int_{0}^{T} t\left(e^{\wedge} 2\right) d t
\end{array}
$$

\section{RESULTS AND ANALYSIS}

In this section, simulation results related to the proposed controller PI-PSO for controlling speed of a Synchronous Reluctance Machine (SRM) will be presented and compared with those obtained by using the controller conventional $P I$. The rated values and parameters used in the simulation program are as follows:

$\begin{array}{lll}\text { Parameters } & \text { Symbols } & \text { Values } \\ \text { Frequency } & f & 50 \\ \text { Power } & P_{n} & 1500 \\ \text { Supply voltage } & V_{n} & 220 / 380 \\ \text { Rated speed } & \Omega_{n} & 100 \\ \text { Poles } & 2 p & 3 \\ \text { Stator resistance } & r_{s} & 1,3 \\ \text { d-axisStator inductance } & L_{d} & 0,060 \\ \text { q-axisStator inductance } & L_{q} & 0,008 \\ \text { Inertia } & J & 0,0013 \\ \text { Friction coefficient } & f_{r} & 0,00004\end{array}$


The main objective of this application is to provide as input a reference speed that must enslave Synchronous Reluctance Machine. For this, two case examples are studied.

In the first case, the reference speed is defined by a echelon which varies between $(100 \mathrm{rpm} / \mathrm{s}$ and $200 \mathrm{rpm} / \mathrm{s})$ to demonstrate the performance and efficiency of the proposed model (PI and PI-PSO) in an extreme case (Fig. $4)$, the mechanical load torque varies between $(O N . m)$ and $(3 N . m)$ (Fig. 5). For the second case, the reference speed is represented by repetitive sequence of trapezoids (Fig. 6), the torque mechanical load being kept constant during the simulation time $\left(T_{m}=3 N . m\right)$ (Fig. 7).

\subsection{First case: Control by echelon}

In this case, the reference speed and mechanical load torque are defined by steps (Fig. 4). Fig. 4 show the time response of the machine to the reference speed using the two control strategies (controllers): the conventional PI and PI-PSO.

Fig. 4 shows the reference speed used as the response time is not achieved in the case of a conventional $P I$ controller. But the time response on using PI-PSO is obtained at time $(t=0.05 \mathrm{~s})$.

Moreover, to illustrate the performance and the efficiency of the proposed model, Fig. 5 show the electromagnetic torque response provided by these two controllers.

The response presented by electromagnetic torque Fig. 5 (blue colour) concerning the conventional PI controller, shows that the oscillations are not attenuated during the time of simulation. In Fig. 5 (red colour), the oscillations are reduced moderately by about $(5 \%)$ by contribution in case of a PI controller.

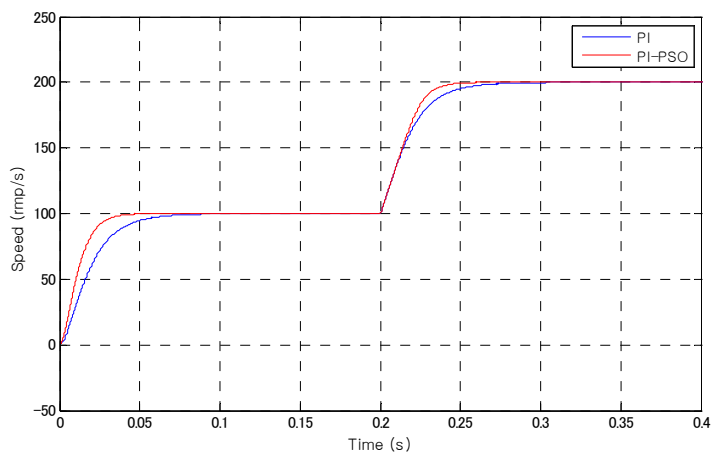

Fig. 4 Speed controller

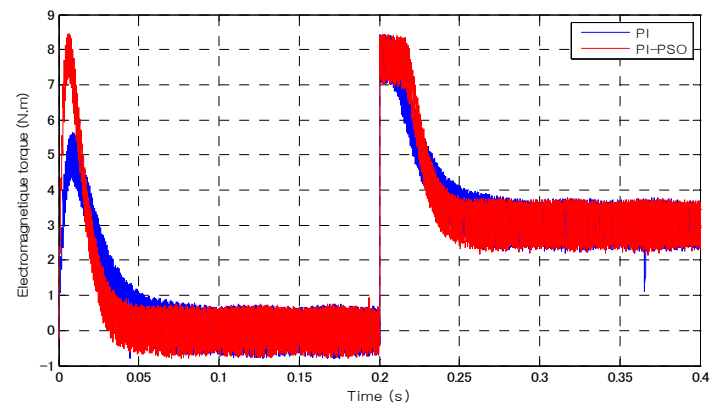

Fig. 5 Electromagnetic torque controller

\subsection{Second case: Control by a trapezoidal sequence}

In this case, the reference speed is defined by a repetitive sequence trapezoids, the torque is fixed to $(3 N . m)$. Fig. 6 shows the speed responses for the two strategies command used.

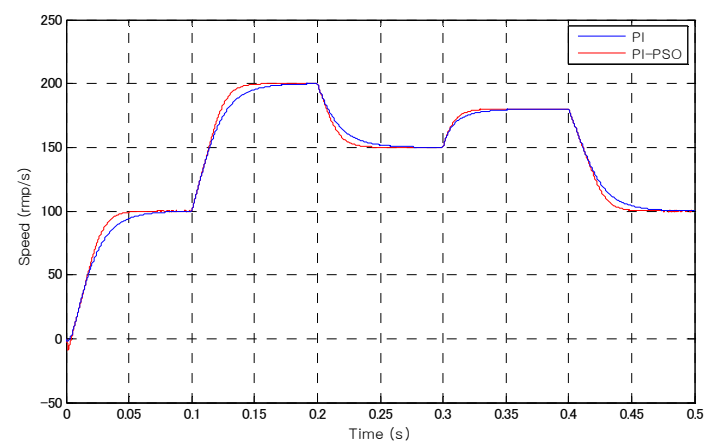

Fig. 6 Speed controller

As illustrated in Fig. 6, the control strategy by particle swarms $P I-P S O$ is more suitable than the other strategy $P I$ Conventional in the different phase control of the SRM in terms of stability and response time required.

Fig. 7 shows the electromagnetic torque response. This figure also confirms the results concluded previously.

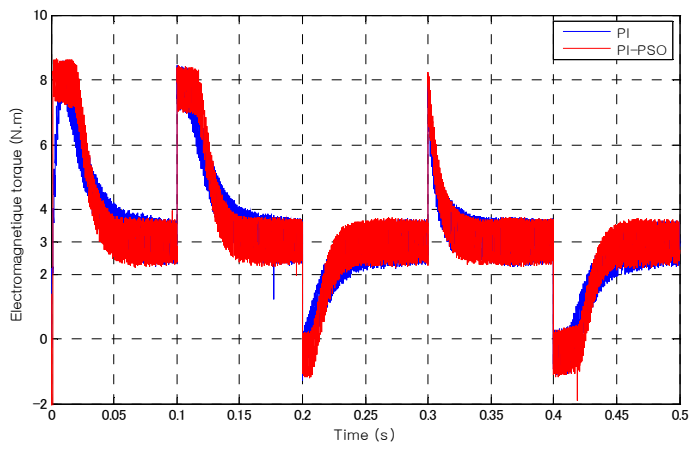

Fig. 7 Electromagnetic torque controller

\section{CONCLUSION}

In conclusion, due to the nonlinear behaviour of the system, disturbances of the variation of parameters and load torque, the conventional control strategy is inadequate for controlling the SRM. In effect, using the conventional $P I$ controller, convergence is obtained occasionally and generally depends on a correct adjustment of PIparameters.

Therefore the controller based on the particle swarm is proposed and compared with that based on conventional $P I$ controller. According to the simulation results, it is clear that the PI-PSO strategy provided better answers speed and accurately than the other strategy.

\section{REFERENCES}

[1] BIRAME, M. - MOKRANI, L. - KADJOUDJ, M. NAAMANE, A. - M'SIRDI, K. N.: Comparative study with and without sensor of speed of a command by Reluctance Motor with smooth stator, Proceedings MAS09, Puerto de La Cruz Tennerife, pp. 27-32, sep. 2009. 
[2] BIRAME, M. - MOKRANI, L. - AZOUI, B. NAAMANE, A. - M'SIRDI, K. N.: Robust DTC of an adjustable speed sensorless switched reluctance motors based on SVM using a PI predictive controller, Journal of Electrical Engineering, Edition 2, Volume 13, 2013.

[3] MOKHTARI, B. - AMEUR, A. - MOKRANI, L. AZOUI, B. - BENKHORIS, M. F.: DTC Applied to Optimize Solar Panel Efficiency, $35^{\text {th }}$ Annual Conference of the IEEE Industrial Electronics Society (IECON 2009), pp. 1118-1123, Alfandega Congress Center, Porto, Portugal, November 3-5, 2009.

[4] RAJESH, M. - VIVEK, R.: Optimum tuning of PI controller parameter for speed control of induction motor, International Journal of Advanced Technology \& Engineering Research (IJATER,), Volume 5, Issue 1, Jan. 2015.

[5] SHAZIA, K. - CHIRAG, G.: An optimization techniques used for economic load dispatch, International Journal of Advanced Technology \& Engineering Research (IJATER), Volume 4, Issue 4, July 2014.

[6] WIBOWO, W. K. - JEONG, S.: Genetic algorithm tuned PI controller on PMSM amplified vector control, of Central South University, 20 (11), 2001, pp. 3042-3048.

[7] BESSEDIK, S. A. - HADI, H.: Prediction of flashover voltage of insulators using least squares support vector machine with particle swarm optimization, Electric Power Systems Research, Elsevier, Vol. 104, June 2013, pp. 87-92.

\section{BIOGRAPHIES}

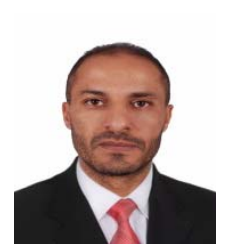

M'hamed Birame was born in Laghouat, Algeria in 18.10.1972. In 2005 he graduated (Magiter) with distinction at the Department of Electrical Engineering of the Faculty of Technology at Technical University in Batna. He defended his $P h D$ in the field of Power Electronics in 2015; his thesis title was "Control for speed sensorless direct torque control (DTC) applied to a variable synchronous reluctance machine $(S R M)$ use of artificial intelligence techniques". Since 2005 he is working as Assistant Professor at Electrical Engineering Department. Laghouat University (Algeria). He is a member of the research group in LEDMASED Laboratory. His main research area includes Modeling of Electrical Machines, Electrical Drives Control, Power Electronics.

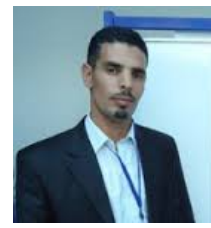

Sid Ahmed Bessedik received the Dipl. Ing. degrees in electrical engineering from the University Ibn Khaldoun Tiaret, Algeria in 2004 and Dipl. Magister in High Voltage from the University of Sciences and Technology of Oran (USTO) Algeria in 2008. From 2009 to 2010, he was an Electrical Engineer in Company Orascom Construction Industries Algeria (OCIA). In 2010, he joined the University Ammar Telidji Laghouat Algeria as assistant professor and researcher at the Laboratoire de Génie Electrique d'Oran (LGEO), where he is a member of High Voltage and Electrical Discharge Group. His main research interestsinclude high voltage insulation, dielectric materials, modeling andcomputation of electrical field in high voltage equipment, Optimizationmethods (Genetic Algorithm, Partial Swarm Optimization), Artificial Intelligence methods (ANN, ANFIS, LS-SVM).
[8] VAMSEE, K. K. - RENUKA, D. N: Particle swarm optimization based direct torque control DTC of induction motor, International Journal of Advanced Research in Electrical, Electronics and Instrumentation Engineering, Vol. 2, Issue 7, July 2013.

[9] ZHOU, B.: Application of particle swarm optimization on DTC for induction motor, IEEE DOI: 10.1109/ICNC, 2008.

[10] EI-LABAN, O. S - ABDEL FATTAH, H. A. EMARA, H. M. - SAKR, A. F.: Particle swarm optimized direct torque control of induction motors, IEEE Trans, 2006.

[11] WAHSH, S. - ELWER, A. - KHALIL, M. NOURELDIN, A.: Tuning PI-Controller Using Particle Swarm Optimization For Control Of Permanent Magnet Synchronous Motor, $5^{\text {th }}$ St. Petersburg workshop in Simulation, RUSSIA, June 26 - July 2, 2005, pp. 239-244.

[12] BENAMEUR, L. - ALAMI J. - LOUKDACHE A. - El IMRANI A.: Particle swarm based PI controller for permanent magnet synchronous machine, Journal of Engineering and Applied Sciences 2 (9) 2007, pp. 13871393.

[13] MITSUKURA, Y. - YAMAMOTO, T. - KANEDA, M.: A design of self-tuning PID controllers using a genetic algorithm, Proc. Amer. Contr. Conf., San Diego, CA, June 1999, pp. 1361-1365

Received January 18, 2016, accepted June 23, 2016

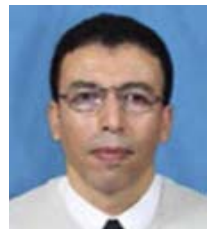

Lakhdar Mokrani was born in Batna, Algeria, in 1970. He obtained his engineer and Ph.D. degrees in electrical engineering, in 1994 and 2005 respectively from Batna University, Algeria. In 1997, he joined the Electrical Engineering Department of Laghouat University, Algeria, as Assistant Lecturer. Since December 2005, he is an Assistant Professor at the same department. He is also a Team Leader of "Control and Energy Management of Electrical Systems" research group in the LACoSERE laboratory, Laghouat University, Algeria. Since 2012, he is a Professor at the same Department. His main research area includes Modeling and CAD of Electrical Machines, Electrical Drives Control and Renewable Energy Systems Control and Management.

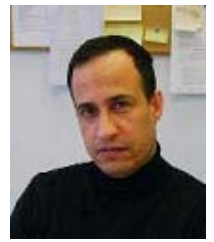

Mohamed Fouad Benkhoris was born in Bou-sâada, Algeria, on September 17, 1963. He has studied at Ecole Nationale Polytechnique d'Alger (ENPA), Algeria, and received the Engineer degree in electrical engineering (1986). In 1991 he obtained his PHD degree in electrical engineering at INP Lorraine (France) and the "HDR" (Habilitation à diriger des recherches) in March 2004. From 1991, he is a Professor at the Departement of Electrical Engineering, of Polytech'Nantes, France. Since 2006 he is Professor at Polytech'Nantes, France. He makes research activities at the laboratrory: "Institut de Recherche en Electronique et Electrotechnique de Nantes Atlantique"(IREENA) Saint Nazaire.His fields of interest are: dynamical modelling, simulation and control of electrical drives and especially multi phase drive, multi-converters systems and embarked network. 